\title{
Prevalence of mitral valve prolapse in primary spontaneous pneumothorax
}

\author{
Zouheir Ibrahim Bitar*, Sherif Ahmed, Amin Elsayed Amin, \\ Khaled Jamal, Mustafa Ridha
}

Adan Hospital, Ministry of Health, Kuwait

Received 25 November 2005; accepted 20 August 2006

KEYWORDS

Mitral valve prolapse;

Pneumothorax

\section{Introduction}

The incidence of primary spontaneous pneumothorax (PSP) in male Arabs is 8.8 per 100,000 per year and it is predominantly a

\footnotetext{
* Corresponding author. PO Box: 46468 Fahahil 64015, Kuwait. Tel.: +965 6043300 .

E-mail address: zbitar2@hotmail.com (Z.I. Bitar).
}

\begin{abstract}
Summary
Background: Mitral valve prolapse (MVP) has been describfd as a colr'mon diagnosis and has been reported in $50 \%$ of patients with primare sp on inlous pneumothorax (PSP). The purpose of this study was to deAs:reins the prevalence of MVP - as diagnosed by 2D-echocardiogrlapneriteria - in spontaneous pneumothorax.

Method: A case-fonfrol. Scudy of 24 pailents W vith PSP, and 40 age-matched

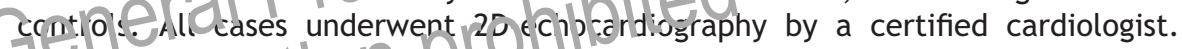

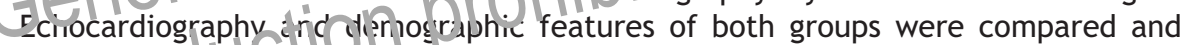
analyzeringin E Hisber's exact test. Classic MVP was defined as superior displacement (A the mirral leaflets of more than $2 \mathrm{~mm}$ during systole and as a maximal leaflet thickness of at least $5 \mathrm{~mm}$ during diastasis, and non-classic prolapse was defined as displacement of more than $2 \mathrm{~mm}$ with a maximal thickness of less than $5 \mathrm{~mm}$.

Results: MVP was found in 9 of the 24 patients (37.5\%) who suffered PSP, compared to 3 out of the $40(7.5 \%)$ age-matched controls $(P=0.008)$. The body mass index (BMI) (weight/height2) was lower in the group with pneumothorax $(P=0.001)$.

Conclusion: In this study, applying an updated definition of MVP, the prevalence of MVP in PSP was lower than previously reported, but was still significantly higher than in the control group.

(c) 2006 General Practice Airways Group. Published by Elsevier Ltd. All rights reserved.
\end{abstract}

disease of young men [1]. PSP occurs mostly through the rupture of a sub-pleural bleb or bullae [2]. Mitral valve prolapse (MVP) has been described as a common disorder, with prevalence estimates ranging from $5 \%$ up to $35 \%$ [3-5]. In a community-based sample of the population, however, prevalence of MVP was 2.4\% [6], lower than previously reported. Echocardiographic MVP has been found in $50 \%$ of patients with PSP 
[7]. Studies describing the three-dimensional shape of the mitral annulus [8,9] have allowed the two-dimensional (2D-) echocardiographic characterization of the prolapse to be refined, thus minimizing false positive diagnoses $[10,11]$.

We used current 2D- echocardiographic criteria to determine the prevalence of MVP in patients with PSP admitted to Adan teaching hospital in the Ahmadi Governorate in Kuwait.

\section{Methods}

\section{Patients}

The study was carried out in the medical department of Adan teaching hospital. Twentyfour consecutive patients were included during a two-year period from November 2002 to November 2004. Patients diagnosed with PSP, in the absence of underlying traumatic and intrinsic pleuropulmonary disease on clinical examination and imaging technique, were included. The control group consisted of forty age-matched asymptomatic Kuwaiti health care workers residing in the same drainage area who were seen consecutively when undergoing routine employment medical examinations. All subjects were physil:alliy examined. The physical eximiraticre infiuded measurement of body $r$ id: $S$ index (BMI - the weight in kilograns divicled by a square of the he ght in meters) and blood pressure, ancuassessment for chest deformities, stigmata of Marfan's syndrome, and the presence of a mitral systolic murmur and mid-systolic click. Patients in both groups were referred for chest X-ray and echocardiography.

\section{Echocardiographic methods}

All subjects underwent standard 2Dechocardiography with a commercially available system, Vivid 7 General Electric, which used a $2.5 \mathrm{MHz}$ transducer. Images were recorded on a $C D$, including complete parasternal, apical and subscostal views, and colour Doppler assessment of the valvular regurgitation. We measured the displacement of the anterior and posterior mitral leaflets in the parasternal and apical long axis views, scanned by tilting the transducer to visualize all the three scallops of the posterior leaflets $[8,9,12]$. The thickness of the mitral leaflets during diastasis was measured from the leading to the trailing edge of the thickest area of the mid-portion of the leaflet, excluding focal areas of thickness and the chordae [13,14]. Each

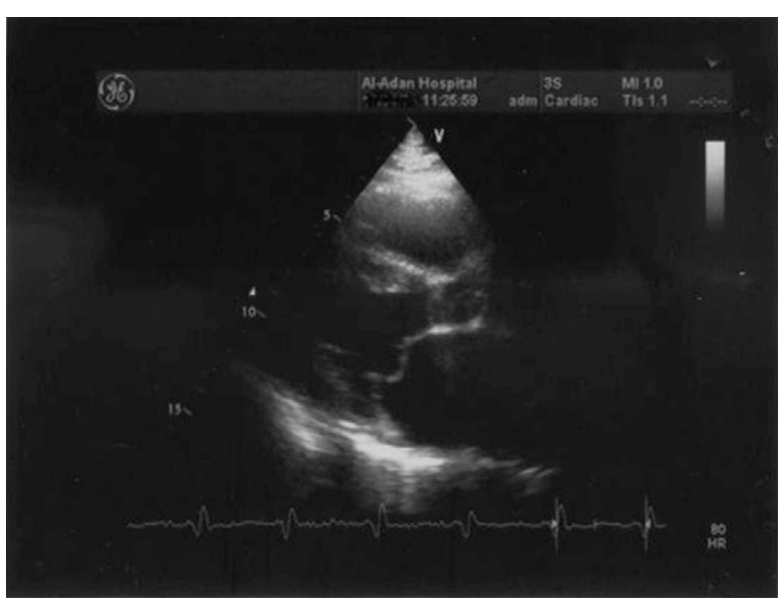

Figure 1 Two-Dimensional Echocardiographic Parasternal Long-Axis View of the Left Ventricle (LV), Showing Prolapse of anterior Mitral Leaflet into the Left Atrium (LA).

leaflet was measured and categorized according to the maximal thickness.

The echocardiograms were classified as showing classic MVP if the mitral valve leaflet displacement exceeded $2 \mathrm{~mm}$ and 10 maximal thickness was at least $5 \mathrm{~mm}$. Ind siowing nonclassic prola psia if displacement exceeded $2 \mathrm{~mm}$ bat the maximal thickness was less than $5 \mathrm{~mm}$.

corderline desrees of displacement $(<2 \mathrm{~mm})$ not aslic cicted with increased leaflet thickness, rnitrili regurgitation, left atrial enlargement and valve-related complication were not included in the definition of prolapse [10] - see Figure 1.

\section{Statistical analysis}

Statistical significance of the difference between the two groups was determined by Fisher's exact test. A $P$-value of $<0.05$ was considered to be significant.

\section{Results}

The demographic characteristics of the study participants are shown in Table 1 . All the patients were male.

Nine patients (37.5\%) with PSP had MVP, of whom three $(12.5 \%)$ showed classical MVP and six patients (25\%) had non-classical MVP. The prevalence of MVP among the control group was $7.5 \%$, with two patients $(5 \%)$ showing classical prolapse and one patient (2.5\%) non-classical prolapse-Table 2.

The BMI was lower $(P=0.001)$ in patients with PSP. Median BMI for the PSP patients was 
Table 1 Demographic characteristics of the Pneumothorax and Control groups

\begin{tabular}{llll}
\hline Characteristics & Pneumothorax $N=24$ & Control group $N=40$ & $95 \% \mathrm{Cl}^{* *}$ \\
\hline Age(years) & $24.8(+5.6)$ & $22.3(+3.2)$ & $(0.289$ to 4.7$)$ \\
Smokers(\%) & $18(75)$ & $34(85)$ & $(0.498$ to \\
Body mass index median $(\mathrm{Kg} / \mathrm{sqm})$ & $19.1^{*}(15.8$ to 21.6$)$ & $23.4(20$ to 29.3$)$ & \\
\hline${ }^{*} p$ value $<0.001$. & & & \\
${ }^{* *} \mathrm{Cl}$ : confidence interval. & &
\end{tabular}

Table 2 Prevalence of mitral valve prolapse in subjects with spontaneuos pneumothorax and control subjects

\begin{tabular}{llll}
\hline Mitral valve prolapse & Pneumothorax $N=24$ & Control group $N=40$ & $95 \% \mathrm{Cl}$ \\
\hline No prolapse $(\%)$ & $15(62.5)$ & $37(92.5)$ & $.005(.004-.007)$ \\
Classical prolapse (\%) & $3(12.5)^{*}$ & $2(5)$ & $.012(.01-.014)$ \\
Non classical $(\%)$ & $6(25)^{* *}$ & $1(2.5)$ & $.082(.001-.003)$ \\
\hline${ }^{*} p$ value $=0.008$. & & & \\
${ }^{*} p$ value $=0.002$. & & &
\end{tabular}

Table 3 Smoking status in relation to mitral valve prolapse in subjects with spontaneous pneumothorax and in control subjects

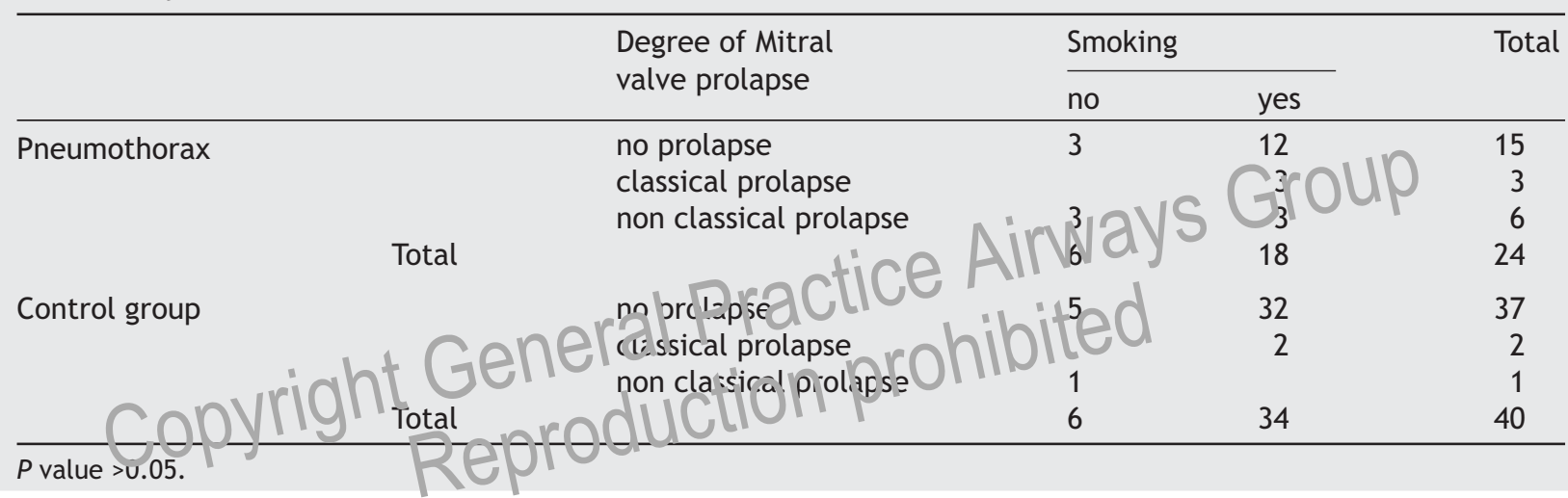

$19.1 \mathrm{Kg} / \mathrm{sqm}$ (range; 15.8 to $21.6 \mathrm{Kg} / \mathrm{sqm}$ ). Median $\mathrm{BMI}$ for the control group was $23.4 \mathrm{Kg} / \mathrm{sqm}$ (range; 20 to $29.3 \mathrm{Kg} / \mathrm{sq}$ ).

Eighteen (75\%) of the PSP subjects were smokers, six of them having MVP, compared to twenty eight (70\%) non-smokers in the control group, three of them having MVP. The difference in incidence of MVP between smokers and non-smokers is not statistically significant - see Table 3 .

\section{Discussion}

The association between PSP and MVP has previously been reported in two studies $[7,15]$. Brear et al. [15] reported an 80\% incidence of MVP in patients with PSP. This high incidence was probably due to using $M$-mode echocardiographic criteria alone in diagnosing MVP - a method which generally exaggerates the diagnosis of MVP. In the second study, Margolite et al. [7] reported an incidence of
$50 \%$ after including 2D-echocardiographic criteria, but still the definition of MVP was less specific. They defined MVP as $>3 \mathrm{~mm}$ of mitral valve displacement, at least $2 \mathrm{~mm}$ of prolapse, and any prolapse. The definition of "any prolapse"' left the diagnosis to observer bias.

The incidence of MVP in PSP in our study is less than has been reported previously. This difference appears to be related to the greater specificity of our criteria together with no loss in sensitivity for the detection of complications $[6,16]$.

Smoking has been shown to increase the risk of contracting PSP [17] and might have a role in the pathogenesis of MVP [18]. Our study did not show a statistically significant difference between the smoking and non-smoking groups in the incidence of MVP in patients with PSP. There were no female patients in our study, in keeping with other studies, since PSP is more prevalent in men and is extremely rare in female Arabs [1].

An abnormal collagen type has been a concomitant finding with MVP in many patients with 
PSP [7] and it has been suggested that PSP and MVP might be a further manifestation of a generalized connective tissue abnormality [19]. Pathological studies have shown disruption of collagen bundles in the leaflets and chordae tendinae of prolapsed mitral valves [20]. Biochemical studies have shown a spectrum of collagen abnormalities in the prolapsed valves. However, MVP is not associated with genetic abnormalities for collagen types I, III, and V. According to echocardiographic evaluation, MVP was noted in $57 \%$ of patients with Marfan's syndrome [21]. It also occurs in types I and II of Ehlers-Danlos syndrome, pseudoxanthoma elasticum, and osteogenesis imperfecta. Pulmonary complications are described in cases of EhlersDanlos syndrome type IV, as established by studies of collage biosynthesis. Reviews of other reported series indicate that pulmonary complications do occur in patients with Ehlers-Danlos syndrome type IV, but they have not resulted directly in patient mortality [22].

\section{Conclusion}

MVP is common in patients with PSP. In this study, the prevalence of MVP in patients with PSP is less than has been reported before, but is st: significantly higher than in controls. The prevalence was higher in patients with a $10 \mathrm{~m}$. M1. There is no association betyee/lsholing and MVP in patient with PSP.

\section{Conflicts of interest}

There are no conflicts of interest to be declared.

\section{References}

[1] Elsonbaty MR, Bitar ZI, Marafie AA, Sharma Prem N. Primary spontaneous pneumothorax in Arabs: does its frequency differ from elsewhere? J Clin Epidemiol 2000;53:631-3.

[2] Anderson B, Nielson JB. Recurrence of spontaneous pneumothorax. Acta-Chir Scand 1965;356(suppl):160-6.

[3] Levy D, Savage D. Prevalence and clinical features of mitral valve prolapse. Am Heart J 1987;113:128-90.

[4] Markiewicz W, Stoner J, London E, Hunt SA, Popp RL. Mitral valve prolapse in one hundred presumably healthy young females. Circulation 1976;534:64-73.

[5] Savage DD, Devereux RB, Garrison RJ, et al. Mitral valve prolapse in the general population.1. Epidemiologic features: The Framingham Study. Am Heart J 1983;106: 577-8.

[6] Freed LA, Levy D, Levine RA, Larson MG, et al. Prevalence and clinical outcome of Mitral-Valve prolapse. N Engl J Med 1999;341:1-7.

[7] Margaliot SZ, Barzilay J, Bar-David M, et al. Spontaneous pneumothorax and mitral valve prolapse. Chest 1986;89: 93-4.

[8] Levine RA, Triulzi MO, Hrrigan P, Weyman AE. The relationship of mitral annular shape to the diagnosis of mitral valve prolapse. Circulation 1987;75:756-67.

[9] Levine RA, Handschumacher MD, Sanfilippo AJ, et al. Three dimensional ehocardiographic reconstruction of the mitral valve, with implications for the diagnosis of mitral valve prolapse. Circulation 1989;80:589-98.

[10] Levine RA, Stathogiannis E, Newell JB, Harrigan P, Weyman AE. Reconsideration of echocardiographic standards for mitral valve prolapse: lack of association between leaflet displacements isolated to the apical four chamber view and independent echocardiographic evidence of abnormality. J Am coll Cardiol 1988;11:1010-9.

[11] Perloff JK, Child JS. Mitral valve prolapse: evolution and refinement of diagnostic techniques. Circulation 1989;80:710-1.

[12] Marks AR, Choong CY, Sanfilippo AJ, Ferre M, Weyman $A E$. Identification of high-risk and low -risk subgroups of patients with mitral -valve prolpase. $N$ Engl J Med 1989;320:1031-6.

[13] Duren DR, Becker AE, Dunning AJ. Long-term follow up of idiopathic mitral valve pro'apse in 300 patients: a prospective study. J Am Col Sardiol oyy 1988; 1:42-7.

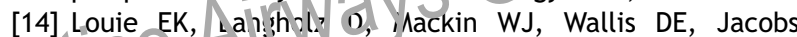
' $V^{\prime}$ '. Jansesophageal echocardiographic assessment of the contribution of intricissue thickness to the appearance of the 7 alice ritral valve in patients with mitral valve Prclapse. J Am Coll cardiology 1996;28:465-71.

[15] Brear SG, Beton D, Yvonne M, Slaven D. Spontaneous pneumothoraces are associated with mitral valve prolapse. Proceedings of the British Thoracic Society 1984;39:219.

[16] David PL, Arthur EW. Mitral Valve Prolapse: Time for a fresh look. Reviews in Cardiovascular Medicine 2001;2:73-81.

[17] Bense L, Eklund G, Wiman LG. Smoking and the increased risk of contracting spontaneous pneumothorax. Chest 1987;92:1009-12.

[18] Bense L, Edhag O, Eklund G, Karlberg KE. Occurrence of mitral valve prolapse in nonsmoker spontaneous pneumothorax patients(letter). Chest 1991;99:791-2.

[19] Groniowski J, Walski M, Szymanska D. Helical collagen fibrils in human lung associated with idiopathic spontaneous pneumothorax. Acta Med Pol 1979;20:397-8.

[20] Mulumudi MS, Vivekananthan K. Mysteries of Mitral valve prolapse: proper treatment requires consideration of all clues. Postgrad Med 2001;110(2):43-54.

[21] Come PC, Forunin NJ, White RI, et al. Echocardiographic assessment of cardiovascular abnormalities in the marfan syndrome: comparison with clinical findings and with roentgenographic estimation of aortic root size. Am J Med 1983;74(3):465-74.

[22] Dowton SB, Pincott S, Demmer L. Respiratory complications of Ehlers-Danlos syndrome type IV. Clin Genet 1996;50: 510-4.

Available online at www.sciencedirect.com ScienceDirect 